\title{
A INFLUÊNCIA DAS ARENAS ESPORTIVAS NA CRIAÇÃO E SOBREVIVÊNCIA DE MICRO E PEQUENOS NEGÓCIOS
}

\section{THE INFLUENCE OF SPORTS ARENAS IN CREATION AND SURVIVAL OF SMALL BUSINESS ENTERPRISES}

\section{Silvia Simoni Orlando}

Mestre em Administração pela Universidade Nove de Julho, São Paulo (SP), Brasil

Data de recebimento: 07-12-2015

Vania Maria Nassif

Data de aceite: 10-03-2017

Doutora em Administração de Empresas pela Universidade Presbiteriana Mackenzie com

Pós-Doutorado em Estratégia e Empreendedorismo pela Fundação Getúlio Vargas e

professora do Programa de Pós-Graduação em Administração da Universidade Nove de

Julho, São Paulo (SP), Brasil

\section{RESUMO}

O futebol é um esporte reconhecido no Brasil como fenômeno cultural e como mobilizador da economia por influenciar diversos segmentos de negócios. Tendo em vista essa característica do esporte, este estudo teve por objetivo identificar a influência das arenas esportivas dos principais clubes de futebol do estado de São Paulo, na criação e sobrevivência de micro e pequenos negócios em seu entorno. As arenas são: Arena Corinthians, Allianz Park, Estádio Cícero Pompeu de Toledo e Estádio Urbano Caldeira. A pesquisa é qualitativa, exploratória e foram entrevistados dez proprietários de micro e pequenas empresas instaladas no entorno dessas arenas. Após as transcrições das entrevistas, os dados foram categorizados e analisados conforme análise de conteúdo. Os resultados apontam que o entorno das arenas oferece oportunidade para pequenos negócios, há espaço para crescimento por serem considerados locais que acolhem um número significativo de pessoas em situações diversas e o empreendedor é fundamental para sobrevivência dos negócios.

Palavras-chave: Identificação de oportunidade; arenas esportivas; micro e pequenas empresas; empreendedores.

\section{ABSTRACT}

Football is a recognized sport in Brazil as a cultural phenomenon and as a mobilizer of the economy by influencing several business segments. Considering this characteristic of the sport, this study aimed to identify the influence of the sports arenas of the main soccer clubs of São Paulo State, in the creation and survival of micro and small businesses in their environment. The arenas are: Corinthians Arena, Allianz Parque, Cícero Pompeu de Toledo Stadium and Urbano Caldeira Stadium. The research is qualitative, exploratory and ten owners of micro and small companies installed in surroundings of these arenas were interviewed. After transcribed, the data were categorized and analyzed according to the content analysis. The results indicate that the arena environment offers opportunities for small businesses, there is space for growth because they are considered places that welcome a significant number of people in different situations and the entrepreneur is fundamental to business survival.

Keywords: Opportunity identification; sport arenas; small business enterprises; entrepreneurs. 


\section{INTRODUÇÃO}

O setor esportivo vem crescendo e se destacando como uma área capaz de promover o desenvolvimento e mobilização da economia em vários países, por meio de geração de emprego e renda (LI; AMMON; KANTERS, 2002; BARCELONA; ROSS, 2004; CHADWICK, 2009). No Brasil não é diferente, entretanto, o esporte de maior expressão em movimentação e concentração econômica no país é o futebol (AZEVÊDO, 2009), capaz de fazer girar toda uma cadeia a seu redor. Como exemplo, podemos destacar as escolinhas de futebol, clubes, assinaturas de revistas, jornais especializados em futebol, canais esportivos de televisão, vendas de ingressos para partidas nos estádios, venda de artigos, materiais e acessórios para prática esportiva, entre outros.

Em alguns países, a movimentação das arenas esportivas já foi identificada como área a ser explorada para geração de renda, por meio da instalação de pequenos negócios relacionados ao esporte, ao clube ou ao evento esportivo em seu entorno. Exemplo disso ocorreu no entorno do Stade Olympique du Colombes, na França. Nas Olimpíadas de 1924, os franceses perceberam ali uma oportunidade e passaram a explorar o local vendendo produtos que faziam menção ao evento esportivo; isso gerou para a região um grande desenvolvimento no âmbito comercial, que continuou a crescer ao longo dos anos (RUBIO, 2005).

No Brasil, embora palco de grandes eventos e considerado o país do futebol, esse tema tem sido pouco explorado cientificamente, suscitando, assim, algumas inquietações ao procurar entender a importância do entorno das arenas esportivas, a influência para a região, economia, cultura, e para o desenvolvimento de negócios.

O estado de São Paulo possui muitos estádios e algumas arenas, e esses dois termos muitas vezes são tratados como similares. A fim de promover melhor entendimento a respeito das discussões estabelecidas por este estudo, foi adotado para todas as instalações esportivas pesquisadas o termo Arena, e não Estádio, apoiado por estudos do BNDES (1997), que definem arenas esportivas pela presença de recursos de iluminação, sonorização, cadeiras retráteis, instalações para transmissão de emissoras de televisão, cadeiras privativas, camarotes com serviços de alimentação e por possuir times considerados âncoras das arenas. Para tal, foi realizado um levantamento para mapear as arenas com tais características, intituladas como as principais arenas dos times de futebol do estado de São Paulo. Assim, a pesquisa foi realizada no entorno das seguintes arenas: Corinthians - Sport Club Corinthians Paulista; Allianz Parque - Sociedade Esportiva Palmeiras; Urbano Caldeira - Santos Futebol Clube e Cícero Pompeu de Toledo- São Paulo Futebol Clube.

O entorno das arenas esportivas foi estabelecido para este estudo devido a sua importância econômica e social, e com base nos estudos de Rubio (2005). Acrescenta-se a esta contribuição o fato do entorno ser entendido como um local que oferece oportunidade de ser explorado por empreendedores (BARON; SHANE, 2007). Não obstante, os micro e pequenos negócios serem geridos por empreendedores, entender as competências empreendedoras (MAN; LAU, 2000) dos proprietários também traz contribuições relevantes neste estudo. Há de se considerar ainda que o segmento de micro e pequenos negócios vem crescendo no Brasil, ocupando lugar importante no cenário empresarial brasileiro, como um dos principais pilares da economia nacional, fonte de emprego e geração de renda (KOTESKI, 2004; MASSEY; CAMPBELL, 2013). Assim, o objetivo desta pesquisa foi o de identificar a influência das arenas esportivas dos principais clubes de futebol do estado de São Paulo na criação e sobrevivência de micro e pequenos negócios em seu entorno. 


\section{O ESPORTE E AS ARENAS}

$\mathrm{Na}$ antiguidade, os esportes foram cultivados como elementos ligados à educação e religião; na Grécia antiga, às instituições militares; na Europa do século XVIII, eram oferecidos para treinamentos militares e fins políticos; no Império Romano, os chamados Jogos Públicos consistiam em espetáculos realizados em circos ou teatros com "corridas de bigas, lutas entre gladiadores, combates com feras e execuções" e surgiram para distrair a população (SIGOLI; DE ROSE JUNIOR, 2004, p. 112). Esses espetáculos atraíam pessoas que tinham o objetivo de diversão e entretenimento. A população torcia e idolatrava os gladiadores que terminavam seus combates vivos (Ibidem). De maneira diferente, no Brasil os torcedores vão até as arenas de futebol para divertirem-se, assistirem ao jogo e torcerem por seu time.

São muitas as razões pelas quais as pessoas buscam as arenas como um ambiente de visitação, sendo considerado um grande atrativo turístico (BOSZCZOWSKI; TEIXEIRA, 2012). A Arena Corinthians, por exemplo, foi projetada com uma estrutura de grande visibilidade, para se tornar um espaço turístico urbano a ser movimentado e explorado, visando à geração de renda e emprego para a cidade e região (ALLIS, 2012).

Coates (2007) afirma que as arenas são capazes de representar uma oportunidade para a criação de micro e pequenos negócios. Esse autor, assim como Julien (2010) chama atenção para a importância da localidade, uma vez que dependendo do local onde a arena se encontra, esta pode trazer rentabilidade e prosperidade para o entorno e região. Outros fatores que podem influenciar nos resultados de pequenos negócios são: ações e competências empreendedoras (MAN; LAU, 2000), sobretudo a identificação de oportunidades por empreendedores (CARLAND; HOY; CARLAND, 1988; SHANE; VENKATARAMAN, 2000).

\section{IDENTIFICAÇÃO DE OPORTUNIDADE}

Como empreendedores percebem possibilidades potencias para geração de lucro? Para Baron e Shane (2007), empreendedores são capazes de identificar ou reconhecer situações em que a exploração de um novo produto, serviço, forma de atuação, ou ainda oportunidade de abertura de um novo negócio, podem estar relacionadas às informações que o indivíduo dispõe.

Empreendedores de pequenas empresas, afeitos à identificação e exploração de oportunidades, demandam iniciativas à procura de um espaço visando à criação, desenvolvimento e sustentabilidade de seus negócios (SHANE; VENKATARAMAN, 2000) e as informações podem estar intimamente relacionadas a fatores cognitivos e às experiências do indivíduo empreendedor. Para Baron e Ensley (2006), o empreendedor possui padrões cognitivos diferenciados, adquiridos no decorrer de sua vida, cujas experiências vividas criam padrões que passam a exercer papel fundamental no estabelecimento de conexões normalmente não identificadas em indivíduos não empreendedores; são essas conexões que se caracterizam como oportunidade empreendedora.

O reconhecimento de uma oportunidade empreendedora se inicia com fatores externos, que podem funcionar como estímulos, propiciando mudanças tecnológicas, políticas, demográficas, climáticas e sociais. Para que esse estímulo leve à identificação de uma oportunidade, os fatores internos são fundamentais, tais como processos cognitivos, conhecimento, informações, competências (BARON; SHANE, 2007), o que pode explicar que um mesmo fato ou situação pode parecer uma oportunidade para alguns e um limitador para outros. Esse paradoxo confirma que tais diferenças são influenciadas pelos fatores internos, crenças e valores (BOSZCZOWSKI; TEIXEIRA, 2012).

Uma pessoa com mais experiência e maior acúmulo de informações e conhecimentos pode 
interferir positivamente no reconhecimento de uma oportunidade. Corroborando esse pensamento, Filion (1999) afirma que além da intuição do empreendedor, o conhecimento e domínio de determinado segmento contribuem com a identificação de uma oportunidade. Encontrada a oportunidade, os empreendedores percorrem o caminho para a abertura de sua empresa, desenvolvimento de produtos ou serviços.

Além dos fatores mencionados, Julien (2010), propõe uma pirâmide que ilustra as ações dos empreendedores, conforme a Figura 1.

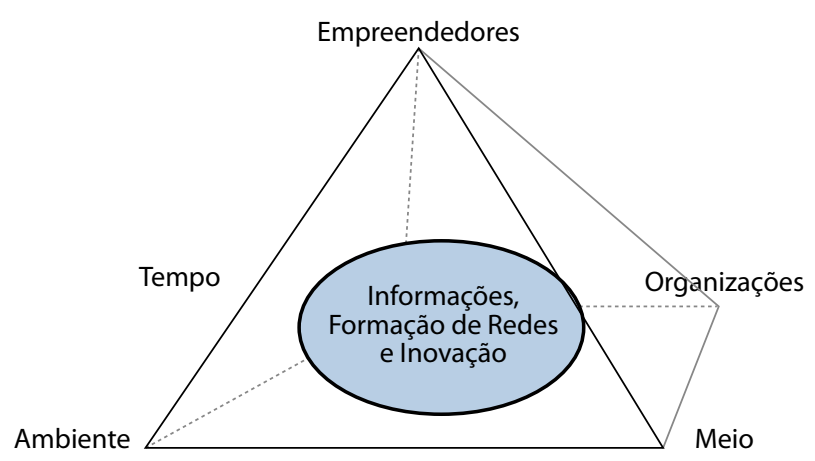

Figura 1 - Pirâmide do Empreendedor

Fonte: Julien (2010).

Para o autor, os empreendedores precisam levar em consideração o tempo, ambiente e meio para melhor aproveitamento das informações, precisam também fazer redes de relacionamento e desenvolverem, por meio de seus negócios, a inovação, garantindo assim a sobrevivência de seus negócios.

\subsection{Micro e pequenas empresas}

As micro e pequenas empresas vêm assumindo lugar de destaque no cenário empresarial brasileiro, com representatividade significativa em geração de empregos e movimentação da economia do país, caracterizando-se como um dos principais pilares da economia nacional (KOTESKI, 2004; MASSEY; CAMPBELL, 2013). As pesquisas vêm apontando um crescimento significativo no número de pequenas empresas. Perry (2001) aponta o surgimento de mais de um milhão de novas empresas a cada ano, sendo que, dessas, 99\% são de micro ou pequeno porte, chegando a 7,1 milhões em dezembro de 2012, representando um crescimento de $26 \%$ em relação ao ano anterior (SEBRAE, 2013).

Esse crescimento foi favorecido por diversos fatores, sendo um deles a criação do Estatuto da Micro e Pequena Empresa - Lei $n^{\circ}$ 9.841/1999 (Idem, 2014), a Lei Geral das Micro e Pequenas Empresas, de 2006, a implantação do Microempreendedor Individual (MEI) em 2009 e a ampliação dos limites de faturamento do Simples Nacional em 2012 (Idem, 2013).

Estudos científicos na área de empreendedorismo identificaram outro fator inquietante para o desenvolvimento de pesquisa em decorrência do crescimento em números de MPEs no Brasil, pela movimentação e contribuição socioeconômica das classes menos favorecidas economicamente do país, chamadas de "base da pirâmide" (RIBEIRO; SEGATTO; COELHO, 2013, p. 57), pois representam o sustento da família (VIANNA; TEIXEIRA; FRANCA, 2013), garantem sua sobrevivência de maneira digna (LIMA, 2001) e muitas vezes o negócio significa a razão de vida (NASSIF; ANDREASSI; SIMÕES, 2011). Motivos esses pelos quais optou-se nesse estudo pelo segmento das micro e pequenas empresas.

Estar à frente dos negócios tem sido um dos fatores de maior relevância para garantir a sobrevivência dos pequenos negócios (NASSIF; ANDREASSI; TONELLI, 2016) pois na maioria dos casos são os empreendedores os maiores responsáveis pela manutenção, crescimento e desenvolvimento da empresa, também pela gestão, tomada de decisões, operacionalização, contato com clientes, fornecedores, administração de problemas e conflitos, além de responder pelo desempenho e resultados da empresa. 
Corroborando esses pressupostos, Wang et al. (2011), afirmam que o empreendedor deve possuir conhecimento sobre gestão, administração e planejamento. E destacam que esses conhecimentos fazem toda diferença para a sobrevivência das MPEs. Para os autores, boa parte dos empreendedores não desenvolvem planejamento, não possuem conhecimento em gestão, tornando esse fato um empecilho para o desenvolvimento de MPEs. Alves et al. (2013) afirmam que proprietários de MPEs não utilizam ferramentas de gestão por desconhecimento; muitos o fazem parcialmente ou de maneira informal e intuitiva, sem um método ou lógica, características essas dos "operadores" identificados em um estudo de Filion (1999), que fazem o que acham que deve ser feito dentro de suas habilidades e capacidades.

A falta de conhecimento e preparo dos dirigentes é também reconhecida como uma dificuldade para gerir MPEs. Diante das dificuldades e limitações, a taxa de sobrevivência de MPEs no Brasil, é de $75,6 \%$, considerando os 24 primeiros meses de existência da empresa (SEBRAE, 2013). Esse número é bastante expressivo ao considerar que $24,4 \%$ das empresas que se estabelecem, fecham em até dois anos (ECKERT et al., 2013; SEBRAE, 2013) e esse número se agrava ainda mais em cinco anos, quando a taxa de mortalidade das MPEs pode chegar a 50\% (SEBRAE, 2014).

Mesmo com a dificuldade de abrir e manter uma micro ou pequena empresa, esse segmento de negócios vem crescendo ano após ano, conforme os índices apresentados pelo SEBRAE (2014). São necessárias diversas competências e conhecimentos, que vão além do desejo de abrir seu próprio negócio. Criar uma empresa é tarefa para "pessoas movidas por um espírito de criação, de busca de oportunidades e de inovação" (LIMA, 2001, p. 2). Esse autor afirma que as micro ou pequenas empresa geridas de forma empreendedora possuem mais chances de obter sucesso e desenvolvimento (Idem, 2010), no entanto, essa é uma tarefa árdua por exigir habilidades que lhe permitam uma atuação dinâmica voltada para resultados (ROCHA, 2014).

\section{PROCEDIMENTO METODOLÓGICO}

O objetivo desta pesquisa foi identificar a influência das arenas esportivas dos principais clubes de futebol do estado de São Paulo na criação e sobrevivência de micro e pequenos negócios em seu entorno. Por se tratar de um tema ainda incipiente, necessitando de dados consubstanciados para melhor entender a dinâmica de micro e pequenas empresas estabelecidas no entorno das arenas esportivas do estado de São Paulo, Creswell (2007) sugere o desenvolvimento de pesquisa qualitativa, que pode ser realizada em cenários naturais e observada sob dois fatores: comportamento e fatos. Assim, optamos pelo método qualitativo, de natureza exploratória e descritiva, cuja interpretação se dá em relação aos relatos dos participantes da pesquisa. Godoy (1995) afirma que os estudos qualitativos básicos possuem três características-chave, são elas: compreender os significados do mundo e experiências dos entrevistados; o pesquisador é o principal instrumento de coleta e análise de dados; o processo de condução da pesquisa é essencialmente indutivo, e pode construir um relato descritivo, detaIhado e rico. Participaram da pesquisa dez empreendedores, selecionados a partir de mapeamento inicial realizado por meio de observação in loco dos pequenos negócios instalados no entorno das arenas pesquisadas. De acordo com a Lei n 12.663/2012, considera-se entorno de arenas esportivas o raio de dois quilômetros ao redor da arena. Nesse raio foi considerado o menor eixo, dado o interesse da pesquisa em identificar se esses negócios são ou não impactados pela existência da arena. Dentro desses critérios foram identificadas 28 empresas instaladas no entorno das quatro arenas pesquisadas. Desse total, dez empreendedores aceitaram participar da 
pesquisa. Os negócios desses empreendedores estão enquadrados dentro dos parâmetros de porte de MPEs estabelecidos pelo IBGE. O instrumento eleito para a coleta de dados foi a entrevista, apoiada em um roteiro semiestruturado, contendo temas relacionados à criação e sobrevivência de MPEs, dificuldades e facilidades e a influência da arena na criação e sobrevivência dos negócios.

O critério de seleção das arenas levaram em consideração a movimentação anual com eventos e programações esportivas, além de serem âncoras dos principais times de futebol do estado de São Paulo.

A Arena Corinthians, do Sport Club Corinthians Paulista, foi construída para ser sede da Copa do Mundo de Futebol - FIFA 2014. Em 12 de junho de 2014, foi palco da cerimônia de abertura da Copa do Mundo, seguida do primeiro jogo oficial do mundial entre Brasil e Croácia. A arena conta com 48 mil lugares e está localizada na Avenida Miguel Ignácio Curi, 111, bairro de Itaquera, na Zona Leste de São Paulo.

A arena Allianz Parque, da Sociedade Esportiva Palmeiras, antigo estádio Palestra Itália, foi inaugurada em 19 de novembro de 2014, possui 43.600 lugares e está localizada na Rua Palestra Itália, 1840, Perdizes, São Paulo. A arena do São Paulo Futebol Clube, Cícero Pompeu de Toledo, fica localizada na Praça Roberto Gomes Pedrosa, número 1, no bairro Morumbi, São Paulo - SP. Possui 72 mil lugares e foi inaugurada em 2 de outubro de 1960. A arena Urbano Caldeira, do Santos Futebol Clube, possui a capacidade de 16.798 lugares e está localizada na Rua Princesa Isabel, s/n, Vila Belmiro, na cidade de Santos - SP.

Todas as entrevistas foram realizadas no próprio estabelecimento dos entrevistados, gravadas com a autorização deles, e transcritas integralmente, visando manter a riqueza dos detalhes nas narrativas dos respondentes. Os dados foram organizados em categorias de respostas a priori e analisados por meio do método de análise de conteúdo, conforme Bardin (2009).

\section{ANÁLISE E DISCUSSÃO DOS RESULTADOS}

Este estudo contou com a participação de proprietários de micro e pequenos negócios instalados no entorno das quatro arenas dos principais times de futebol do estado de São Paulo. Os negócios mapeados são em sua maioria do ramo alimentício e todos são categorizados como micro negócios, de acordo com a classificação de porte de empresas do IBGE.

Os motivos apresentados pelos respondentes a respeito de como surgiu a ideia do negócio, complementado com a ocupação anterior, demonstram uma grande diversidade de razões que levaram cada empreendedor a criar sua empresa, conforme Quadro 2.

Antes da apresentação da análise dos aspectos dificultadores e facilitadores para criação e sobrevivência desses negócios, vale ressaltar que a quantidade dos aspectos facilitadores se apresenta em maior quantidade na sobrevivência do que na criação desses negócios, e ao contrário disso, na fase de criação da empresa, os empreendedores encontram mais dificuldades do que facilidades, conforme apresentado nos quadros 3 e 4 .

As dificuldades encontradas pela maioria dos entrevistados na criação da empresa estão relacionadas a ações administrativas, organizadoras e estratégicas, confirmando as teorias de Wang et al. (2011) e Alves et al. (2013), que destacam a necessidade e importância de conhecimento nas áreas administrativas, visando a sobrevivência dos negócios. Além disso, os autores apontam em suas pesquisas que há falta de conhecimento dos empresários de micro e pequenos negócios nessa área do conhecimento, acarretando sérios problemas em sua sobrevivência. No quesito facilidades, estão relacionadas com o contexto e as bases de apoio, como conhecimentos específicos para gerir os negócios, apoio da família, criação de linhas de crédito, embora na mobilização de recursos para a criação das empresas, nenhum dos entrevistados declarou sobre a utilização desse recurso. 
Quadro 1 - Perfil das Empresas Pesquisadas

\begin{tabular}{|c|c|c|c|c|}
\hline Empreendedor(a) & Empresa & Atividade & $\begin{array}{l}\text { Ano de } \\
\text { criação }\end{array}$ & $\begin{array}{l}\text { Número de } \\
\text { funcionários }\end{array}$ \\
\hline Alberto F. de Oliveira Jr. & Confraria do Alemão & Bar e Restaurante & 1994 & 3 \\
\hline Antônio Ribeiro & Estádio Café & Lanchonete & 2005 & 3 \\
\hline Gustavo F.Aguirre & Palestra Mania & Artigos exclusivos do Palmeiras & 2000 & 2 \\
\hline Laércio Pinto M. Carneiro & Palmeiras Lanches & Restaurante e Lanchonete & 1995 & 2 \\
\hline Luis Fernando Cesar & Restaurante Xiqueirão & Restaurante e Lanchonete & 2015 & 4 \\
\hline Terry Goldstroten & Salgado Mania & Salgados e Lanches & 2014 & 2 \\
\hline Valdecir Martins da Silva & PorqueriaStore & $\begin{array}{l}\text { Artigos relacionados ao } \\
\text { Palmeiras }\end{array}$ & 2015 & 1 \\
\hline Valgilvan M. Cavalcante & Vila Saad & Bar e Restaurante & 2008 & 5 \\
\hline Wesley Machado & W.Dog & Lanchonete & 2012 & 2 \\
\hline William Starlon A. Pessoa & Tempero Brasil & Restaurante e Lanchonete & 2010 & 8 \\
\hline
\end{tabular}

Fonte: Organizado pelas autoras.

Quadro 2 - Criação da empresa

\begin{tabular}{|c|c|c|}
\hline Empreendedor(a) & Atividade Anterior & Criação da Empresa \\
\hline Alberto F. de Oliveira Jr. & $\begin{array}{l}\text { Gerente de } \\
\text { lanchonete }\end{array}$ & $\begin{array}{l}\text { Oportunidade de ter seu sustento (RIBEIRO et al., 2013; VIANNA et al., 2013) e } \\
\text { ainda estar mais próximo de seu time do coração }\end{array}$ \\
\hline Antônio Ribeiro & Camelô & Necessidade, sustento da família (RIBEIRO et al., 2013; VIANNA et al., 2013). \\
\hline Gustavo F.Aguirre & Estudante & Ter seu próprio negócio (BOAVENTURA; MELO, 2012). \\
\hline $\begin{array}{l}\text { Laércio Pinto M. } \\
\text { Carneiro }\end{array}$ & Estudante & $\begin{array}{l}\text { Dar continuidade ao negócio do pai, sustento da família, (RIBEIRO et al., 2013; } \\
\text { VIANNA et al., 2013). }\end{array}$ \\
\hline Luis Fernando Cesar & $\begin{array}{l}\text { Funcionário de } \\
\text { empresa privada }\end{array}$ & $\begin{array}{l}\text { Ter seu próprio negócio e não trabalhar mais como empregado (BOAVENTURA; } \\
\text { MELO, 2012). }\end{array}$ \\
\hline Terry Goldstroten & $\begin{array}{l}\text { Oficial de Justiça } \\
\text { (França) }\end{array}$ & Razão para viver (NASSIF et al., 2014). \\
\hline Valdecir Martins da Silva & Camelô & $\begin{array}{l}\text { Oportunidade de trabalhar com o que ama e necessidade de sustento (RIBEIRO et } \\
\text { al., 2013; VIANNA et al., 2013). }\end{array}$ \\
\hline Valgilvan M. Cavalcante & $\begin{array}{l}\text { Funcionário de } \\
\text { empresa privada }\end{array}$ & $\begin{array}{l}\text { Ter seu próprio negócio e não trabalhar mais como empregado (BOAVENTURA; } \\
\text { MELO, 2012). }\end{array}$ \\
\hline Wesley Machado & $\begin{array}{l}\text { Funcionário de } \\
\text { multinacional }\end{array}$ & Sonho de ter o próprio negócio (GARTNER, 2003). \\
\hline $\begin{array}{l}\text { William Starlon A. } \\
\text { Pessoa }\end{array}$ & $\begin{array}{l}\text { Funcionário de } \\
\text { empresa privada }\end{array}$ & $\begin{array}{l}\text { Ter seu próprio negócio e não trabalhar mais como empregado (BOAVENTURA; } \\
\text { MELO, 2012). }\end{array}$ \\
\hline
\end{tabular}

Fonte: Organizado pelas autoras.

Quadro 3 - Criação das MPEs

\begin{tabular}{|l|l|}
\hline \multicolumn{2}{|c|}{ Criação da empresa } \\
\hline Dificuldades & Facilidades \\
\hline $\begin{array}{l}\text { Achar um ponto comercial que seja bom para o negócio e as } \\
\text { mesmo tempo que esteja dentro do orçamento disponível para o o } \\
\text { investimento. }\end{array}$ & $\begin{array}{l}\text { Possuir vínculo com o clube. Estar diretamente ligado aos } \\
\text { torcedores e a todas as frentes vinculadas ao time de futebol } \\
\text { relacionadas à arena. }\end{array}$ \\
\hline $\begin{array}{l}\text { Lidar com produtos licenciados pelos clubes. } \\
\text { Conhecimento técnico em administração, aprimoramento e } \\
\text { preparo. }\end{array}$ \\
\hline $\begin{array}{l}\text { Dificuldade no início do negócio, para se tornar conhecido, } \\
\text { formar clientela e adquirir a confiança dos fornecedores. }\end{array}$ & Linhas de crédito para micro e pequenos empresários. \\
\hline
\end{tabular}


Quadro 3 - Criação das MPEs

\begin{tabular}{|l|l|}
\hline \multicolumn{2}{|c|}{ Criação da empresa } \\
\hline Dificuldades & Facilidades \\
\hline $\begin{array}{l}\text { Encontrar pessoas qualificadas para trabalhar, comprometidas ou } \\
\text { com disposição e interesse em aprender. }\end{array}$ & Apoio da família. \\
\hline Falta de recursos financeiros para abrir o negócio. & \\
\hline $\begin{array}{l}\text { Falta de informação para abrir uma empresa, por onde começar, } \\
\text { documentação, preparo do local, normas, leis, recursos } \\
\text { obrigatórios. }\end{array}$ & \\
\hline Burocracia pesada e morosa. & \\
\hline
\end{tabular}

Fonte: Organizado pelas autoras.

Quadro 4 - Sobrevivência de MPEs

\begin{tabular}{|c|c|}
\hline \multicolumn{2}{|c|}{ Sobrevivência de MPEs } \\
\hline Dificuldades & Facilidades \\
\hline $\begin{array}{l}\text { Acumulo de funções do proprietário, por ser uma micro } \\
\text { empresa, tem fazer quase tudo. }\end{array}$ & $\begin{array}{l}\text { Possuir vínculo com o time. Estar diretamente ligado aos torcedores e } \\
\text { a todas as frentes vinculadas ao time de futebol relacionado à arena. }\end{array}$ \\
\hline Lidar com produtos licenciados pelos clubes. & $\begin{array}{l}\text { Parcerias com fornecedores de produtos comercializados na empresa } \\
\text { em troca de publicidade. }\end{array}$ \\
\hline Depender exclusivamente da movimentação da arena. & Presença do proprietário na direção do negócio. \\
\hline Não ter vocação para o negócio. & Conhecimento em administração e gestão de empresas. \\
\hline Impostos & $\begin{array}{l}\text { Tradição do negócio, estar há muitos anos bem estruturado no } \\
\text { mercado. }\end{array}$ \\
\hline O peso da responsabilidade sobre o negócio. & $\begin{array}{l}\text { A lealdade, fanatismo e devoção do torcedor faz com que } \\
\text { ele consuma produtos e serviços relacionados ao clube, } \\
\text { independentemente do time estar ganhando ou não campeonatos. }\end{array}$ \\
\hline \multirow[t]{5}{*}{ Formar um time, capacitar pessoas. } & Movimentação da Arena. \\
\hline & Ter organização administrativa e financeira do negócio. \\
\hline & Linhas de crédito para micro e pequenos empresários. \\
\hline & Apoio da família. \\
\hline & Ter bons e amplos relacionamentos. \\
\hline
\end{tabular}

Fonte: Organizado pelas autoras.

Não obstante os resultados da pesquisa evidenciarem que a arena foi a principal influenciadora na criação de sete dos dez negócios pesquisados, ficou claro que, para a sobrevivência dos negócios, a arena foi fundamental em todos os casos. Essa contribuição se dá principalmente devido a seu público, além de ela oferecer diversas possibilidades de exploração de oportunidades. Essas oportunidades variam desde a criação de um novo produto, serviço, até a decisão pelo nome do estabelecimento, ambientação, decoração, atendimento, entre outros, dada a proximidade da arena com o público que a frequenta (BARON; SHANE, 2007).
Da Costa et al. (2008) argumentam ainda que a estrutura da arena e os eventos que nela ocorrem, podem ser um atrativo para a criação de pequenos negócios, a exemplo de como o entorno do Centennial Park em Atlanta - EUA se desenvolveu nas Olimpíadas de 1996. A região atraiu centenas de negócios comerciais e construções tornando-se uma região privilegiada na cidade.

No caso desta pesquisa, serão apresentados os principais fatores que contribuíram para a criação do negócio sob a influência arena.

A Confraria do Alemão foi instalada em frente à arena Urbano Caldeira para atender principalmente ao público de torcedores frequentadores 
dos jogos de futebol. Alemão (apelido de Alberto Oliveira Jr.) já possuía uma lanchonete no interior da arena há quase vinte anos quando decidiu abrir seu bar. Percebeu que havia um bar fechado bem em frente à arena e identificou uma boa oportunidade. O empresário afirma que em dias de jogos chega a vender de quinze a vinte peças de pernil em lanches, seu produto carro chefe e que, além de torcedores, recebe também pessoas da imprensa que já o conhecem e param em seu bar para comer o lanche:

Todo mundo sabe que eu gosto do Santos então o pessoal vem aqui. O meu bar aqui é um ponto de referência. Eu tenho mais fregueses em dia de jogos de fora do que da própria cidade, e o pessoal do interior chega cinco, seis horas antes do jogo e já vem pra cá. (Alberto Oliveira Jr.).

O restaurante e lanchonete Xiqueirão, de Luis Cesar, foi criado estrategicamente em frente à arena Allianz Parque para ser um bar temático do time do Palmeiras. O nome do restaurante pode parecer estranho, mas para o público do futebol, e em especial para os torcedores do Palmeiras é completamente adequado, pois faz menção aos "por$\cos ^{\prime \prime}$, apelido adotado pelos torcedores do clube.

A partir da construção da arena foi vislumbrada a ideia de comprar um imóvel próximo, e apareceu essa oportunidade na qual foi adquirido esse imóvel já com a intenção de criar essa casa temática em relação ao Palmeiras por estar em frente a arena. A vinda pra cá foi em função da construção da arena. [...] O nome Lancheteria Xiqueirão, é de chiqueiro mesmo, que recebe os torcedores porcos no bom sentido. Em dia de jogo a movimentação é muito grande... nós trabaIhamos muito em dias de jogos... sempre vem muita gente de fora, muita gente do interior... e na parte de baixo tem o porão do porco que a gente utiliza para servir porções e cerveja em lata pra não ter problema. (Luis Cesar).
A loja Palestra Mania de Gustavo, no início vendia produtos esportivos diversos, mas a escoIha do local se deu devido à existência do clube Sociedade Esportiva Palmeiras. Para Gustavo, o público que frequenta um clube, que faz atividade física, academia, natação, futebol e outros esportes é um público potencial para sua loja de artigos esportivos.

Com o tempo e a movimentação do estádio Palestra Itália (hoje arena Allianz Parque), Gustavo foi identificando a oportunidade da venda de produtos do time de futebol Palmeiras. Percebeu que havia procura por produtos e aos poucos foi se especializando em produtos exclusivos do Palmeiras. Esse caso corrobora Fernandes (2013), que afirma que as arenas afetam a cadeia produtiva do futebol "abrindo espaço para demandas por novos produtos e serviços e constituindo-se em uma oportunidade para potencializar novos empreendimentos e negócios associados" (Ibidem, p. 63).

A ideia foi ficar em frente ao clube para vender artigos esportivos em geral. Mas, aos pouquinhos, a gente foi se direcionando para artigos exclusivo do palmeiras porque tinha procura e dos últimos anos para cá houve um aumento grande porque os clubes descobriram esse filão de artigos licenciados, então nos especializamos. Há cinco anos que nós temos uma loja virtual, então a gente vende para o Brasil inteiro. (Gustavo Aguirre).

Valdecir Silva e seu sócio vivem a cultura palmeirense, ambos torcem pelo time, fazem parte da torcida organizada e da escola de samba do Palmeiras. Essas foram as principais razões para que criassem a Porqueria Store. Esse nome faz menção ao apelido dos torcedores do Palmeiras, os "porcos". Por essa razão, na criação do negócio, a escolha do local veio junto com a escolha dos produtos, do nome da loja e do público que eles queriam atingir. 
Eu não teria aberto em outro local. A ideia de abrir aqui foi porque somos palmeirenses, somos da mancha, tem a arena e a gente vive aqui... a gente vem de segunda a segunda aqui. Se fosse para ter aberto em outro local não teria sentido, porque em dia de jogo tem muito, mas muito mais movimento. Vem torcida do Palmeiras de todos os lados, torcida organizada do Palmeiras. Na segunda-feira nós não abrimos por falta de movimento, porque o clube também não abre (Valdecir Silva).

No Quadro 5 é possível compreender a posição de Julien (2010) no que tange a influência do meio; e Baron e Shane (2007), quando percebe-se que, mesmo que a arena não tenha sido fator decisivo para a criação do negócio, esta torna-se uma fonte de inspiração para a identificação de oportunidades. Cada empreendedor(a) explorou a arena de acordo com sua estratégia e criatividade.

Anderson e Goeree (1997) consideram que a localidade é o fator de maior relevância para o sucesso de negócios de varejo, assim como para o marketing o produto é o fator mais importante, e esta pesquisa ratifica essa afirmação. Nos casos pesquisados neste estudo, pode-se identificar a localidade como um dos fatores que contribuem com a sobrevivência de todas as empresas pesquisadas, que possuem três anos de existência ou mais. Esse recorte se deve ao índice de mortalidade de $24,4 \%$ das MPEs nos primeiros dois anos de vida, de acordo com o SEBRAE (2013).

Laércio, que atua na direção da empresa de seu pai há vinte anos, declarou que tem adiado seu

Quadro 5 - Referência Empresas e Arenas

Referência à Arena
organizada do Santos e possui treze tatuagens do
time pelo corpo. e o brasão do time está
estampado na fachada do estabelecimento.
O bar Vila Saad é conhecido como o Bar do são-
paulino. Gil se prepara para receber torcedores
nos dias de jogos.
Por estar próximo à Arena Corinthians, a W.Dog
criou os lanches temáticos durante a Copa do
Mundo de 2014. Em 2015, lançou o Dog
Corinthiano e faz promoções para torcedores em
dias de jogos.
O restaurante tem uma parede com brasões da
Sociedade Esportiva Palmeiras e em dias de
jogos serve a "Porção do Palmeiras".

Fonte: Organizado pelas autoras. 
desejo de atuar como advogado devido ao sucesso do negócio. Durante a reforma do antigo estádio Palestra Itália, o negócio manteve-se com bom movimento devido à grande concentração de mão de obra das empreiteiras, e desde a inauguração da arena Allianz Parque, em novembro de 2014, a lanchonete vem superando as expectativas de movimentação.

Eu sou formado em direito, advogado. Meu irmão também e queríamos parar com a lanchonete, mas com a perspectiva da reinauguração da arena nós preferimos ficar mais um tempinho pra ver como ia funcionar, mesmo porque nos quatro anos que a arena ficou fechada para reforma, tinha muita mão de obra aqui, trabalhadores que consumiam aqui. Então a arena influenciou bastante, como te falei, mesmo com o momento difícil do país, sempre tem um evento, um jogo que te salva. Eu tenho amigos que tem restaurantes em Pinheiros e eu vejo a dificuldade que eles estão passando... o que me mantém aqui até agora realmente é a arena. (Laércio Carneiro).

Gustavo, por sua vez, criou sua empresa sob a influência da arena, mais especificamente interessado no público que frequentava o clube social do Palmeiras. Com o tempo, percebeu o interesse do público nos produtos exclusivos do time e hoje sua empresa relaciona-se totalmente com a arena e com o contexto. Sobrevive de produtos licenciados do clube, e seu público é formado por torcedores e afetos ao Palmeiras. Esse posicionamento corrobora Julien (2010), que afirma que empreendedores conseguem explorar e tirar vantagem do meio, não somente para a criação de uma empresa, mas para sua sobrevivência e desenvolvimento.

A inauguração da nova arena trouxe pra gente a possibilidade de ter dia de jogo aqui... então dia de jogo hoje faz diferença porque tem uma movimentação bem maior. Além de que tem muita gente que vem do interior, de outros estados assistirem jogos, e esse pessoal não tem a possibilidade de comprar nossos produtos nas cidades deles, então dias de jogo são sempre dias muito bons. [...] O bom da arena é que o torcedor compra desde um abajur até uma espátula para limpar a panela, desde que seja do Palmeiras [...]. (Gustavo Aguirre).

No caso de Valgilvan, que embora seja torcedor do time São Paulo, não escolheu a localidade para abrir sua empresa devido à existência da arena, mas sim por conveniência: surgiu a oportunidade e estava dentro do orçamento. Entretanto, Valgilvan rapidamente identificou a oportunidade de explorar o contexto local, a existência da arena e a movimentação de torcedores em dias de jogos (BARON; SHANE, 2007; JULIEN, 2010). Seu bar possui ambientação e decoração nas cores do time do São Paulo e em dias de jogos o bar promove um acolhimento aos torcedores, principalmente os que vêm de outras cidades e chegam com até cinco horas de antecedência.

O bar estando caracterizado pelas cores do time do São Paulo atrai o torcedor porque as pessoas tem referência, - "vamos nos encontrar lá no bar São Paulino". O futebol aqui é muito importante, em dia de jogo todos ganham. Se é dia de jogo grande, as pessoas chegam aqui 5 horas antes pra beber e comer, saem na hora do jogo e quando termina o jogo eles ainda passam aqui...então o jogo representa $40 \%$ ou mais da lucratividade, por exemplo, um dia de jogo vende por uma semana de trabalho. (Valgilvan Cavalcante).

Diferente de Valgilvan, Willian já tinha em mente que sua empresa deveria ser instalada em uma região que contasse com estruturas que viessem a contribuir com a sobrevivência do negócio, como universidades, regiões com concentração de empresas e escritórios ou estádios de futebol.

Eu procurei vários negócios, vários lugares que fossem próximos a faculdades, estádios de futebol com 
movimento de gente, claro. Próximos de empresas e diversos comércios que viessem a sustentar o estabelecimento... dar demanda ao estabelecimento. (Willian Pessoa).

A oportunidade para Willian surgiu na região da arena Allianz Parque, enquanto esta ainda encontrava-se em obras. Segundo Willian, nesse período não havia muita procura naquela região, e ele conseguiu adquirir o imóvel por um valor menor do que havia encontrado no entorno do Estádio Municipal Pacaembu, também na cidade de São Paulo, e na região da arena do São Paulo Futebol Clube, no bairro Morumbi. Esse comportamento caracteriza-se como identificação de oportunidade. Willian foi capaz de perceber que logo que a arena fosse inaugurada a região seria valorizada, e estava certo de que a movimentação da arena contribuiria com seu negócio, o que de fato aconteceu.

A movimentação do estádio contribui bastante com o sucesso do negócio. Antes era boa, agora está ótimo. Essa explosão veio muito depois que a arena abriu. A abertura da arena deu um up muito grande no faturamento. Por exemplo, se eu ganhava 8 reais, hoje eu ganho 25 reais, a questão do extra da arena, você pode elevar preço... pode cobrar mais caro, pode ter uma cobrança diferente em dia de jogo, que é um cliente que está vindo procurar o serviço... a demanda cresce e tem muito pouco comércio pra atender em dias de jogo, então você pode elevar o preço (Willian Pessoa).

Terry, dona da Salgado Mania, percebe que em dias de jogos vende muito mais coxinhas do que em dias normais, embora seu negócio não esteja relacionado com a arena ou o time de futebol, e que os torcedores que chegam mais cedo para assistir ao jogo passeiam pelo Shopping Itaquera, então ela já sabe que em dias de jogos o faturamento aumenta, assim como Antônio, que afirma que em dias de jogos se prepara para receber um grande volume de torcedores, que se concentram na região dos quiosques no terminal Itaquera sempre após os jogos. Segundo Antônio, muitos torcedores lancham nos quiosques devido ao alto custo dos produtos no interior da arena.

Já a W. Dog beneficiou-se da existência da arena de maneira mais direta. Com a realização da Copa do Mundo de Futebol no Brasil, em 2014, tendo a Arena Corinthians como uma das sedes para a realização dos jogos, região de instalação da W.Dog, Wesley percebeu uma oportunidade e inovou: criou o "lanche da torcida". Pesquisou os ingredientes mais comuns de cada país e elaborou um lanche que lembrasse a cultura local, além de produzir pães nas cores das bandeiras dos países. A inovação foi um sucesso, deu tão certo que Wesley não parou. No início do ano 2015, criou o "Lanche Corinthiano", um sanduíche de pernil, típico de estádios de futebol, com pão nas cores preta e branca, as cores do clube.

Para Coates (2007), existem defensores dos estádios de futebol como promotores do desenvolvimento econômico local. Estes trazem como principal argumento a movimentação da instalação esportiva, em especial em dias de jogos, promovendo mais lucros para os negócios em seu entorno, e observa-se que nos casos apresentados, é exatamente isso que acontece, a localidade passa a ser um ator do desenvolvimento desses negócios (JULIEN, 2010).

\section{CONSIDERAÇÕES FINAIS}

Esta pesquisa teve como principal objetivo identificar a influência das arenas esportivas dos principais clubes de futebol do estado de São Paulo, na criação e sobrevivência de micro e pequenos negócios em seu entorno. Para tanto, foram analisados os entornos das arenas dos principais clubes de futebol do estado de São Paulo: Santos Futebol Clube, São Paulo Futebol Clube, Sociedade 
Esportiva Palmeiras e Sport Club Corinthians Paulista.

De acordo com Julien (2010), se os empreendedores e os negócios são as condições necessárias para manter o desenvolvimento, um meio empreendedor e inovador constitui condição suficiente para assegurá-lo. Este autor afirma que o meio é o lugar e ao mesmo tempo o mecanismo coletivo que pode explicar e facilitar os diferentes laços sociais, permitindo o desabrochar de um espírito empreendedor coletivo, fonecendo recursos de base, tais como a informação e meios para transformá-la em conhecimento, a fim de enfrentar os desafios do mercado. Assegura ainda que o meio é um elemento-chave do empreendedorismo regional, intitulando-o como "a construção social do mercado" (Ibidem, p. 163).

Da mesma forma, Baron e Shane (2007) pontuam que a localidade pode ser um elemento de relevância quando o empreendedor inicia uma ideia de negócio. Esses autores afirmam que para o empreendedor iniciar uma empresa, precisa explorar oportunidades, reconhecer o que há no entorno do local escolhido e assim identificar as vantagens e desvantagens que o local pode oferecer.

Considerando a importância da localidade, os resultados desta pesquisa evidenciam que o entorno das arenas esportivas pode proporcionar ao empreendedor uma oportunidade para criação e sobrevivência de um negócio. As arenas são complexos públicos que acolhem um número significativo de pessoas na ocasião de eventos, não apenas esportivos, mas também de shows, exposições dentre outras modalidades.

\subsection{Contribuição do estudo}

O empreendedor afeito a criação de um negócio pode usufruir e explorar oportunidades temáticas, conforme o que a arena oferece. Não obstante o meio servir como um recurso importante, ele propicia a geração de uma cultura empreendedora que pode apoiar iniciativas de negócios, e com isso passar a ser reconhecido como um ambiente empreendedor, atraindo pessoas com diferentes propósitos para a criação de um negócio.

Pelos resultados da pesquisa, os empreendedores, de maneira geral, ainda não identificaram o entorno das arenas como uma oportunidade para estabelecerem seus negócios, haja vista os poucos negócios estabelecidos no entorno destas e a pouca exploração das marcas (clube, arena, time de futebol). Dessa forma, o entorno das arenas exportivas, se explorado por empreendedores, pode se transformar em um grande complexo de exploração da arena, do clube e dos times de futebol.

Assim, a pirâmide do empreendedor adaptada de Julien (2010) pode servir de inspiração para geração de um ambiente empreendedor, trazendo resultados para o entorno e para a população estabelecida nas imediações.

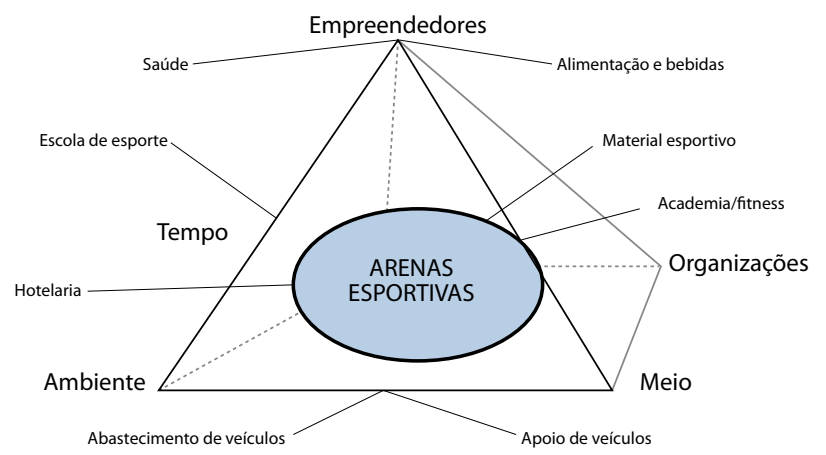

Figura 2 - Negócios no entorno das arenas Fonte: adaptado de Julien (2010), desenvolvida pelas autoras.

Para que essas oportunidades emerjam, é necessário um olhar diferenciado para o desenvolvimento de um ambiente empreendedor, apoiado por políticas públicas de fomento ao desenvolvimento regional, além de proporcionar um ambiente que motive investidores a fomentar e contribuir com os empreendedores na criação e desenvolvimento de seus negócios. 


\subsection{Limitações do estudo}

Por ser um tema ainda pouco pesquisado no Brasil, este estudo contou com aporte teórico reduzido, sobretudo ao se referir às arenas esportivas brasileiras. Esse fato caracteriza uma das dificuldades encontradas para o desenvolvimento da pesquisa e ao mesmo tempo uma oportunidade para estudos futuros.

\subsection{Sugestões para estudos futuros}

Esse estudo não tem um fim em si mesmo. Muitos elementos foram identificados no decorrer do estudo e podem ser aprofundados em pesquisas futuras, como: replicação deste estudo em outros estados brasileiros, para chegar a compreensão da realidade do país; estudos a respeito do impacto das arenas esportivas brasileiras na economia local; a importância das arenas esportivas para a o desenvolvimento e valorização da região; entender se existem e como funcionam as políticas públicas de desenvolvimento regional a partir do contexto (da localidade); pesquisar o empreendedor informal que atua no entorno das arenas esportivas, principalmente em dias de jogos, procurando conhecer as principais dificuldades e razões pelas quais ele não se formaliza.

\section{AGRADECIMENTOS}

Agradecemos à Fundação de Amparo à Pesquisa do Estado de São Paulo (Fapesp) pelo apoio a este estudo.

\section{REFERÊNCIAS}

ALLIS, T. Projetos urbanos e turismo em grandes cidades: o caso de São Paulo. 2012. 273 f. Tese (Doutorado em Arquitetura e Urbanismo) - Faculdade de Arquitetura e Urbanismo da Universidade de São Paulo, São Paulo, 2012.

ALVES, J. N. et al. A utilização do planejamento estratégico como ferramenta de gestão na pequena empresa. Revista da Micro e Pequena Empresa, Campo Limpo Paulista, v. 7, n. 2, p. 80-100, 2013.

ANDERSON, S. P.; GOEREE, J. K.; RAMER, R. Location, location, location. Journal of Economic Theory, New York, v. 77, n. 1, p. 102-127, 1997.

AZEVÊDO, P. H. O esporte como negócio: uma visão sobre a gestão do esporte nos dias atuais. Revista Estudos, Goiânia, v. 36, n. 5, p. 929-939, 2009.

BARCELONA, B.; ROSS, S. C. M. An analysis of the perceived competencies of recreation sport administrators. Journal of Park and Recreation Administration, Urbana, IL, v. 22, n. 4, p. 25-42, 2004.

BARDIN, L. Análise de conteúdo. Lisboa: Edições 70, 2009.

BARON, R. A.; ENSLEY, M. D. Opportunity recognition as the detection of meaningful patterns: evidence from comparisons of novice and experienced entrepreneurs. Management Science, Baltimore, v. 52, n. 9, p. 1331-1344, 2006.

BARON, R.A.; SHANE, S.A. Empreendedorismo: uma visão do processo. São Paulo: Thomson Learning, 2007.

BOSZCZOWSKI, A. K.; TEIXEIRA, R. M. O empreendedorismo sustentável e $\mathrm{O}$ processo empreendedor: em busca de oportunidades de novos negócios como solução para problemas sociais e ambientais. Revista Economia \& Gestão, Belo Horizonte, v. 12, n. 29, p. 109-127, 2012. 


\section{REFERÊNCIAS}

BRASIL. Presidência da República. Casa Civil. Subchefia para Assuntos Jurídicos. Lei n 12.663, de 5 de junho de 2012. Dispõe sobre as medidas relativas à Copa das Confederações FIFA 2013, à Copa do Mundo da FIFA de 2014 e aos eventos relacionados, que serão realizados no Brasil. Diário Oficial da União, Poder Executivo, Brasília, DF, 2012. Seção 1, p. 3.

CARLAND, J. W.; HOY, F.; CARLAND, J. A. C. "Who is an entrepreneur?" is a question worth asking. American Journal of Small Business, Saskatoon, p. 33-39, 1988. Disponível em: <https://goo.gl/16A0FB>. Acesso em: 29 maio 2017.

CHADWICK, S. From outside lane to inside track: sport management research in the twenty-first century. Management Decision, New Jersey, v. 47, n. 1, p. 191-203, 2009.

COATES, D. Stadiums and arenas: economic development or economic redistribution? Contemporary Economic Policy, Morgantown, v. 25, n. 4, p. 565-577, 2007.

CRESWELL, J. W. et al. Qualitative research designs: selection and implementation. The Counseling Psychologist, Miami, v. 35, n. 2, p. 236-264, 2007.

DA COSTA, E. A. Gestão estratégica: da empresa que temos para a empresa que queremos. São Paulo: Saraiva, 2008.

ECKERT, A. et al. O perfil empreendedor na graduação: um estudo comparativo entre ingressantes e concluintes. Revista Pensamento Contemporâneo em Administração, Rio de Janeiro, v. 7, n. 2, p. 61-76, 2013.

FILION, L. J. Empreendedorismo: empreendedores e proprietários-gerentes de pequenos negócios. Revista de Administração, São Paulo, v. 34, n. 2, p. 5-28, 1999.

GEM - GLOBAL ENTREPRENEURSHIP MONITOR. Empreendedorismo na região sudeste do Brasil. São Paulo, 2013.

GODOY, A. S. Introdução à pesquisa qualitativa e suas possibilidades. Revista de Administração de Empresas, São Paulo, v. 35, n. 4, p. 65-71, 1995.

JULIEN, P. A. Empreendedorismo regional e economia do conhecimento. São Paulo: Saraiva, 2010.

KOTESKI, M. A. As micro e pequenas empresas no contexto econômico brasileiro. Revista FAE Business, Curitiba, v. 8 n. 4, p. 16-18, 2004.

LIMA, E. O. A formação em empreendedorismo face à realidade do pequeno empresário brasileiro a partir de estudos de vanguarda, o que devemos enfatizar? In: Treinamento para Atualização da Equipe do EMPRETEC, 2001, Brasília, DF. Brasília, DF: Sebrae Nacional, 2001.

Estratégia de pequenas e médias empresas: uma revisão. REGE - Revista de Gestão, São Paulo, v. 17, n. 2, p. 169-187, abr./jun. 2010.

LI, M.; AMMON, R.; KANTERS, M. Internationalization of sport management curricula in the United States: a national faculty survey. International Sports Journal, Rosemead, n. 6, v. 2, p. 178-194, 2002.

MAN, T. W. Y.; LAU, T. The context of entrepreneurship in Hong Kong: An investigation through the patterns of entrepreneurial competencies in contrasting industrial environments. Journal of Small Business and Enterprise Development, Bingley, v. 12, n. 4, p. 464-481, 2005. 


\section{REFERÊNCIAS}

MAN, T. W. Y.; LAU, T. The entrepreneurial competencies of SME Owner/Managers in the Honk Kong services sector: A Qualitative Analysis. Journal of Enterprising Culture, Singapore, v. 8, n. 3, p. 235-254, set. 2000.

MASSEY, K. B.; CAMPBEL, N. Human resources management: big problem for small business? The Entrepreneurial Executive, London, v. 18, p. 77-88, 2013.

NASSIF, V. M. J.; ANDREASSI, T.; SIMÕES, F. Competências empreendedoras: há diferença entre empreendedores e intraempreendedores? Revista de Administração e Inovação, São Paulo, n. 8, v. 3, p. 33-54, 2011.

NASSIF, V. M. J.; ANDREASSI, T.; TONELLI, M. J. Critical incidents among women entrepreneurs: Personal and professional issues. Revista de Administração, São Paulo, v. 51, n. 2, p. 212-224, 2016.

PERRY, S. C. The relationship between written business plans and the failure of small businesses in the U.S. Journal of Small Business Management, New Jersey, v. 39, n. 3, p. 201-208, jul. 2001.

RIBEIRO, R. E. M; SEGATTO, A. P; COELHO, T. R. Inovação social e estratégia para a base da pirâmide: mercado potencial para empreendedores e pequenos negócios. Revista de Empreendedorismo e Gestão de Pequenas Empresas, São Paulo, v. 2, n. 2, p. 55-72, 2013.

SEBRAE - SERVIÇO BRASILEIRO DE APOIO ÀS MICRO E PEQUENAS EMPRESAS. Relatório de gestão do exercício de 2014. Brasília, DF, 2014. Disponível em: <http://bit. ly/2paNrmu>. Acesso em: 7 abr. 2017.

Sobrevivência das empresas no Brasil. Brasília, DF, 2013. (Coleção estudos e Pesquisas). Disponível em: <http://bit.ly/2nTJ7If>. Acesso em: 7 abr. 2017.

SHANE, S.; VENKATARAMAN, S. The promise of entrepreneurship as a field of research. Academy of Management Review, New York, v. 25, n. 1, p. $217-$ 226, 2000.

SIGOLI, M. A.; DE ROSE JUNIOR, D. A história do uso político do esporte. Revista Brasileira Ciência e Movimento, Brasília, DF, v. 12, n. 2, p. 111-119, 2004.

WANG, C.; WALKER, E.; REDMOND, J. Explaining the lack of strategic planning in SMS: the importance of owner motivation. Perth, AU: Edith Cowan University, 2011. 